\title{
Are mood disorders associated with frequent emergency department visits? Question answered, or a dialogue just beginning?
}

\author{
Quynh Doan ${ }^{1} \cdot$ David Barbic $^{2}$ (D)
}

Received: 9 November 2021 / Accepted: 16 November 2021

(C) The Author(s), under exclusive licence to Canadian Association of Emergency Physicians (CAEP)/ Association Canadienne de Médecine d'Urgence (ACMU) 2021

The rise in emergency department (ED) utilization for mental health and substance use (MHSU) presentations is well established [1,2]. The high prevalence of underlying MHSU concerns among ED care users, compared to general population statistics, has also been reported [2]. In this issue of CJEM, Fehlmann et al. report a strong association between patients with mood disorders and frequent ED use [3]. This work adds to our understanding of the impact of MHSU on ED utilization. The authors suggest that how EDs provide care and attention to co-existing MHSU conditions may influence how well we address our patients' healthcare needs beyond management of the acute presentation. This idea is consistent with previous work demonstrating that high-yield interventions for alcohol use disorder [4] and suicidal behaviour [5] can decrease repeat ED visits.

The investigators' handling of the data, analyses, and interpretation of the results are internally valid, rigorous and commendable. Their discussion of the study's limitations are thorough and relevant. They appropriately highlight that the lack of information around reasons for the frequent ED visits, prevents us from identifying pertinent interventions to target frequent ED users. If these frequent ED visits are MHSU related, this would suggest a gap in community-based MHSU resources. However, if these are for acute exacerbations of chronic illnesses, or for low acuity primary care issues, this would suggest the need for more holistic approaches to healthcare services, and possible gaps in the existing primary care framework. Existing evidence from youth and the young adult population highlights the value of investing in such low barrier community

David Barbic

david.barbic@gmail.com

1 Department of Pediatrics, UBC; BC Children's Hospital, Vancouver, BC, Canada

2 Department of Emergency Medicine, UBC, Centre for Health Evaluation and Outcomes Sciences, Vancouver, BC, Canada based, multidisciplinary clinical settings, with an emphasis on MHSU concerns [6, 7]. Innovative work in Canada (Foundry, BC; Youth Wellness Hubs, Ontario), Australia (headspace) and Ireland (Jigsaw) has shown that low barrier, integrated MHSU services in a "one-stop shop" model leads to high levels of patient satisfaction and safety, as well as symptomatic and functional improvement [8].

A significant limitation to this study, unforeseen to the investigators and beyond their control, is the impact of the COVID-19 pandemic. The pandemic has altered both the delivery of care and service utilization by patients, in so many ways and to such a degree, that any analyses of healthcare utilization using pre-pandemic data are now of questionable value. There is evidence that the pandemic has led to an increase in ED visits for disordered eating behaviour [9], and alcohol use disorder [10], yet the effects on visits for opioid overdoses [11], and suicidal ideation are unclear [9]. Furthermore, the impaired ability to access primary care resources due to the pandemic, has led to a proliferation in virtual care options. Although not universally beneficial, some services have demonstrated significant benefit in diverting a majority of patients from busy, and overwhelmed EDs [12]. Unfortunately, the immediate and longterm impact of such virtual care options for patients with MHSU concerns is unclear. Given the uncertainty around the duration of this pandemic, ongoing evaluation of ED utilization patterns, their associated causes and necessary adjustment to resource allocation, will be of outmost importance to optimize our capacity to deliver safe and effective emergency care.

Conflict of interest All authors declare that they have no conflict of interest. 


\section{References}

1. Chiu M, Gatov E, Vigod SN, Amartey A, Saunders NR, Yao $\mathrm{Z}$, et al. Temporal trends in mental health service utilization across outpatient and acute care sectors: a population-based study from 2006 to 2014. Can J Psychiatry Rev Can Psychiatr. 2018;63(2):94-102.

2. Matsumoto C-L, O'Driscoll T, Lawrance J, Jakubow A, Madden S, Kelly L. A 5 year retrospective study of emergency department use in Northwest Ontario: a measure of mental health and addictions needs. CJEM. 2017;19(5):381-5.

3. Fehlmann CA, Miron-Celis M, Chen Y, Perry J, Eagles D. Association between mood disorders and frequent emergency department use: a cross-sectional study. Can J Emerg Med. 2021. https:// doi.org/10.1007/s43678-021-00204-w.

4. Barata IA, Shandro JR, Montgomery M, Polansky R, Sachs CJ, Duber HC, et al. Effectiveness of SBIRT for alcohol use disorders in the emergency department: a systematic review. West J Emerg Med. 2017;18(6):1143-52.

5. Inagaki M, Kawashima Y, Kawanishi C, Yonemoto N, Sugimoto $\mathrm{T}$, Furuno $\mathrm{T}$, et al. Interventions to prevent repeat suicidal behavior in patients admitted to an emergency department for a suicide attempt: a meta-analysis. J Affect Disord. 2015;1(175):66-78.

6. Mathias S, Tee K, Helfrich W, Gerty K, Chan G, Barbic SP. Foundry: Early learnings from the implementation of an integrated youth service network. Early Interv Psychiatry. 2021. https://doi.org/10.1111/eip.13181.
7. McGorry P, Trethowan J, Rickwood D. Creating headspace for integrated youth mental health care. World Psychiatry. 2019;18(2):140-1.

8. Rickwood DJ, Mazzer KR, Telford NR, Parker AG, Tanti CJ, McGorry PD. Changes in psychological distress and psychosocial functioning in young people visiting headspace centres for mental health problems. Med J Aust. 2015;202(10):537-42.

9. Chadi N, Spinoso-Di Piano C, Osmanlliu E, Gravel J, Drouin O. Mental health-related emergency department visits in adolescents before and during the COVID-19 pandemic: a multicentric retrospective study. J Adolesc Health. 2021;69(5):847-50.

10. Rennert-May E, Leal J, Thanh NX, Lang E, Dowling S, Manns B, et al. The impact of COVID-19 on hospital admissions and emergency department visits: a population-based study. PLoS ONE. 2021;16(6):e0252441.

11. Root ED, Slavova S, LaRochelle M, Feaster DJ, Villani J, DefioreHyrmer J, et al. The impact of the national stay-at-home order on emergency department visits for suspected opioid overdose during the first wave of the COVID-19 pandemic. Drug Alcohol Depend. 2021;228:108977.

12. Ho K, Lauscher HN, Stewart K, Abu-Laban RB, Scheuermeyer $\mathrm{F}$, Grafstein E, et al. Integration of virtual physician visits into a provincial 8-1-1 health information telephone service during the COVID-19 pandemic: a descriptive study of HealthLink BC Emergency iDoctor-in-assistance (HEiDi). CMAJ Open. 2021;9(2):E635-41. 